\title{
El monumento a Dardo Rocha en La Plata
}

The Monument to Dardo Rocha in La Plata

\author{
Ricardo González \\ Facultad de Filosofía y Letras \\ Instituto Teoría e Historia del Arte "Julio E. Payró" \\ Universidad de Buenos Aires-Argentina \\ ricardogonzalezmarchetti@gmail.com
}

\section{Resumen}

El trabajo da cuenta del encargo del monumento que conmemora al fundador de la ciudad de La Plata, su descripción material e iconográfica y las circunstancias, tanto locales como políticas y económicas, en que se generó el encargo, las que se propone, influyeron su concepción y programa icónico.

Palabras clave: Monumento conmemorativo, Dardo Rocha, Patrimonio Cultural.

\begin{abstract}
The work gives an account of the commission of the monument that commemorates the founder of the city of La Plata, its material and iconographic description, and the circumstances, both local and political as economical, in which the commission was generated and which, it is proposed, influenced its conception and iconic program.
\end{abstract}

Keywords: Memorial, Dardo Rocha, Cultural heritage.

Recibido: 30 de abril $2021 \cdot$ Aceptado: 16 de julio 2021 


\section{El contexto}

En la sesión del Concejo Deliberante de la ciudad de La Plata del $1^{\circ}$ de enero de 1928, el concejal Vicente Espeche señaló que la ciudad estaba en deuda con su fundador, proponiendo la erección de un monumento al Dr. Dardo Rocha (Municipalidad de la Plata, Actas del Concejo Deliberante, sesión del $1^{\circ}$ de enero de 1928: 38). El proyecto se adelantaba en 4 años al quincuagésimo aniversario de a fundación de la ciudad, plazo realista para el desarrollo de una obra ambiciosa, pese a que los concejales estimaron que podría ser inaugurado el 19 de noviembre de ese mismo año, fecha de la conmemoración que suele suscitar el espíritu inaugural de las autoridades locales. Aceptada la propuesta de Espeche, la máquina burocrática se puso en marcha: en la sesión del 4 de abril se presentó un “Mensaje del Departamento Ejecutivo y proyecto de ordenanza referente a la erección de un monumento a la memoria del fundador de La Plata Doctor Dardo Rocha" y el concejal Pedro Álvarez, luego de apuntar el carácter de la "suscripción que se proyecta", pidió el pase del proyecto a la comisión respectiva (Municipalidad de la Plata, Actas del Concejo Deliberante, sesión del 4 de abril de 1928: 49).

La suscripción pública era un método corriente para sufragar monumentos de personajes a los que se suponía la opinión pública debía estar agradecida y que la inopia de las instituciones no permitía llevar a cabo. Finalmente el aporte municipal fue de m\$n 7204 (Municipalidad de la Plata, Actas del, Concejo Deliberante, sesión del 28 de noviembre de 1934: 146-150) y la Provincia solventó la suma de m\$n 35.000 (Legislatura de la Provincia de Buenos Aires). El edil Nicolás Martínez apuntó poco antes de la inauguración, "que estaban pendientes" aún "la realización de obras de mejoramiento de la plaza Rocha" (Municipalidad de la Plata, Concejo Deliberante, sesión del 18 de octubre de 1934), donde se instalaría el monumento. Es decir, que no solo no había hasta el momento conmemoración alguna del fundador sino que la plaza que lo recordaba tenía un estado inacabado o deficiente.

En la concepción ideológica-urbanística de Dardo Rocha, las plazas y los parques cumplían un papel central.

En primer lugar, por la necesidad de ventilación de la trama edificada que proponían las teorías higienistas, pero también porque constituían, en la perspectiva republicana que se proponía, una especie de nuevo templo ciudadano donde no solo el esparcimiento tenía lugar, sino también el diálogo y el debate, base de la formación de la opinión pública y el consenso. A su vez este objetivo requería de la puesta ante oculos de los ciudadanos de un discurso visual capaz de promover la conciencia acerca de los proyectos políticos implicados: las esculturas y los monumentos corrían con esa función (González, 2004: 51 ss.). Como lo señaló Maurice Agulhon respecto al proceso francés, modelo del argentino: "Entre otras formas de propaganda impactantes, acentuadas, destinadas a un público sencillo y nuevo, el didactismo figurativo y monumental fue inmediatamente utilizado" (Agulhon, 1992).

En el caso de La Plata, la traza, con su retícula cruzada por las diagonales, conformaba una red cuyos núcleos articuladores eran justamente las plazas, 
a su vez rodeadas en muchos casos de edificios representativos de los diferentes poderes, en una concepción del espacio urbano que se remontaba a los antiguos circuitos barrocos y que el barón Hausmann había implementado en la Francia de Napoleón III como préfet de la Seine. El “eje monumental", que se extendía desde el Bosque hasta la plaza de la Municipalidad, pasando por la de la Legislatura, recorría los cuatro centros del poder: el Palacio de Gobierno provincial, la Legislatura, la Municipalidad y la Catedral. Su programa icónico estaba centrado en tres ejes: el historicista, que remitía a los héroes de Mayo, especialmente a Moreno y también a Rivadavia, mentores del proyecto liberal, a los que se agregó en 1914 San Martín. Luego un conjunto de personificaciones clásicas representando los valores del proyecto político-económico: la agricultura, la ganadería, el comercio marítimo y fluvial, la industria, las ciencias y las artes. Finalmente, montado sobre estos significados prácticos, el aura republicana del clasicismo que las personificaciones ponían a la vista (González, 2004: 55 ss.).

Transversalmente a este eje institucional-ideológico, las tres avenidas que delinean el centro de la ciudad -1, 7 y 13-, presentaban una iconografía más variada y en cierta forma, más localizada. En el tramo céntrico de la avenida 7, las plazas que lo limitan estaban dedicadas al fundador (Plaza Rocha, 7 y 60) y a la confraternidad ítalo-argentina (Plaza Italia, 7 y 44), es decir, agentes locales de la historia. De todos modos, como vimos, todavía en 1934 este cuidado programa conmemorativo y simbólico, distaba de estar en su apogeo y ni siquiera los mismos espacios verdes se hallaban en condiciones.
El abandono del plan inicial se debía a varias causas. Naturalmente la sempiterna falta de recursos, pero también el naufragio de la fundación misma durante las primeras décadas de existencia de La Plata, hecho debido en primer lugar al fracaso de la candidatura de Rocha a la presidencia, que era una faceta no dicha pero indudable del objetivo fundacional, y que terminó descartada por Mitre y por Roca en razón de su pésima administración bonaerense, dando lugar a la postulación de Juárez Celman. En segundo lugar, por la pérdida de uno de los pocos horizontes factibles de desarrollo económico de la ciudad, que, sin industrias ni producción propia al momento de la fundación, como lo señalaron algunos observadores extranjeros en esos años, [1] se especulaba pudiera reemplazar al obsoleto puerto de Buenos Aires, lo que se estrelló con el nuevo diseño portuario presentado por Eduardo Madero e impulsado por Roca. Finalmente, por la crisis económica originada en la deuda externa que estalló en 1890 y que terminó con la presidencia del cordobés Juárez (Balestra, 1986).

Esta situación llevó al progresivo deterioro o paralización de las obras emprendidas y a la triste coexistencia de los presuntuosos palacios renacentistas, símbolo de lo que se pensaba sería "la nueva Buenos Aires" con la modestia y el descuido del conjunto. En un momento se dudó de la misma sustentabilidad de la ciudad y las miradas dejadas por quienes la visitaron hacia el cambio de siglo no dejan dudas. Frederick Alcock escribió en 1902:

[La ciudad] está repleta de magníficos edificios públicos en su mayoría a medio 
terminar; algunos ni siquiera alcanzaron ese punto, sino que quedaron sin ventanas, expuestos al deterioro que causa el tiempo, como monumentos de un loco orgullo que erige para sí palacios y templetes con medios insuficientes. [...] siéntense en un banco en una de las anchas calles donde crece el pasto, con alguno de los palacios descuidados y a medio terminar a la vista, y piensen cuales habrán sido los sueños de esplendor que hicieron surgir esta ciudad tal cual es de la noche a la mañana y la desolación de los soñadores, cuando llegaron a la triste conclusión de que sus aspiraciones nunca se harían realidad. (Barcia, 1982: 217)

Las cosas habían sin embargo comenzado a mejorar lentamente hacia 1910, cuando ya descartado el ilusorio proyecto inicial, el establecimiento de frigoríficos y otras industrias comenzaron a revitalizar la vida platense. Ese año y las dos décadas siguientes, se desarrollaron algunos de los conjuntos escultóricos emblemáticos, especialmente los de la plaza Moreno y se dio forma al paseo del Bosque (el Bois de Boulogne local) y al Zoológico. Las instituciones políticas, que habían quedado relegadas por la falta de peso de la ciudad a una mera administración local por períodos en manos de un comisionado del gobernador comenzaron a disponer de un espacio más autónomo que se manifestaba en el Concejo Deliberante y en la figura del intendente, que implicaba una representación propia y electiva.

El marco de la recuperación era también el reencarrilamiento de la economía nacional luego de la crisis del 90 y la visualización de un horizonte prometedor que alcanzó su forma apoteótica en los festejos y las presentaciones del Centenario. Una nueva escena política, renovada luego de la ley Sáenz Peña por la emergencia del radicalismo hacía correr nueva savia por las venas del conjunto $\mathrm{y}$, naturalmente de la capital provincial, si bien la provincia seguía en manos de los conservadores. En este contexto expansivo, en el que la ciudad y sus instituciones ganaban en estabilidad y confianza, parece normal la rememoración del hecho fundacional y la tardía celebración de su agente. Antes, había que componer la plaza.

\section{La obra}

La obra fue encargada al escultor César Sforza. Había nacido en 1893, se había formado en la Academia Nacional de Bellas Artes y participaba en el Salón Nacional, donde había obtenido el segundo premio en 1918 con Nostalgia y el primero en 1920 con Cariátide, un desnudo femenino sedente. En 1921 había ganado el premio municipal con Torso de mujer y el año siguiente el premio mayor con una media figura femenina titulada Floreciendo. En 1937 había ganado el premio-adquisición en la Exposición Internacional de París y había expuesto en Río de Janeiro y en Nueva York, era pues, un escultor establecido, que además desarrolló un perfil intelectual y docente, ya que justamente en los años en que trabajaba en el monumento que tratamos, ganó la cátedra de escultura en la Escuela de Bellas Artes de la UNLP, donde fue miembro, junto al compositor Gilardo Gilardi y otros artistas de la comisión directiva de la revista Imagen, órgano de la Escuela que había fundado Ángel Nessi. 
Sforza era, en 1928, un escultor reconocido y tenía ya en su haber encargos monumentales de escala, como el de Los Fundadores, en la ciudad de Bahía Blanca, que le había sido solicitado el año anterior y el dedicado al ingeniero Luis Huergo en la ciudad de Buenos Aires, que estaba realizando y se inauguraría en 1929. Su obra tenía un sentido figurativo sintético y un potente sentido de masa, tendencia compartida con otros escultores pos-académicos argentinos del momento, como Alfredo Bigatti, cuyo monumento a Mitre limagen 1| emplazado en el Bosque platense pocos años más tarde (1942), constituye, con el dedicado a Rocha, un par fundamental en la escultura pública de la época, en la que el clasicismo subyace a través de la experiencia modernista filtrada en los conjuntos escultóricos de Bourdelle.

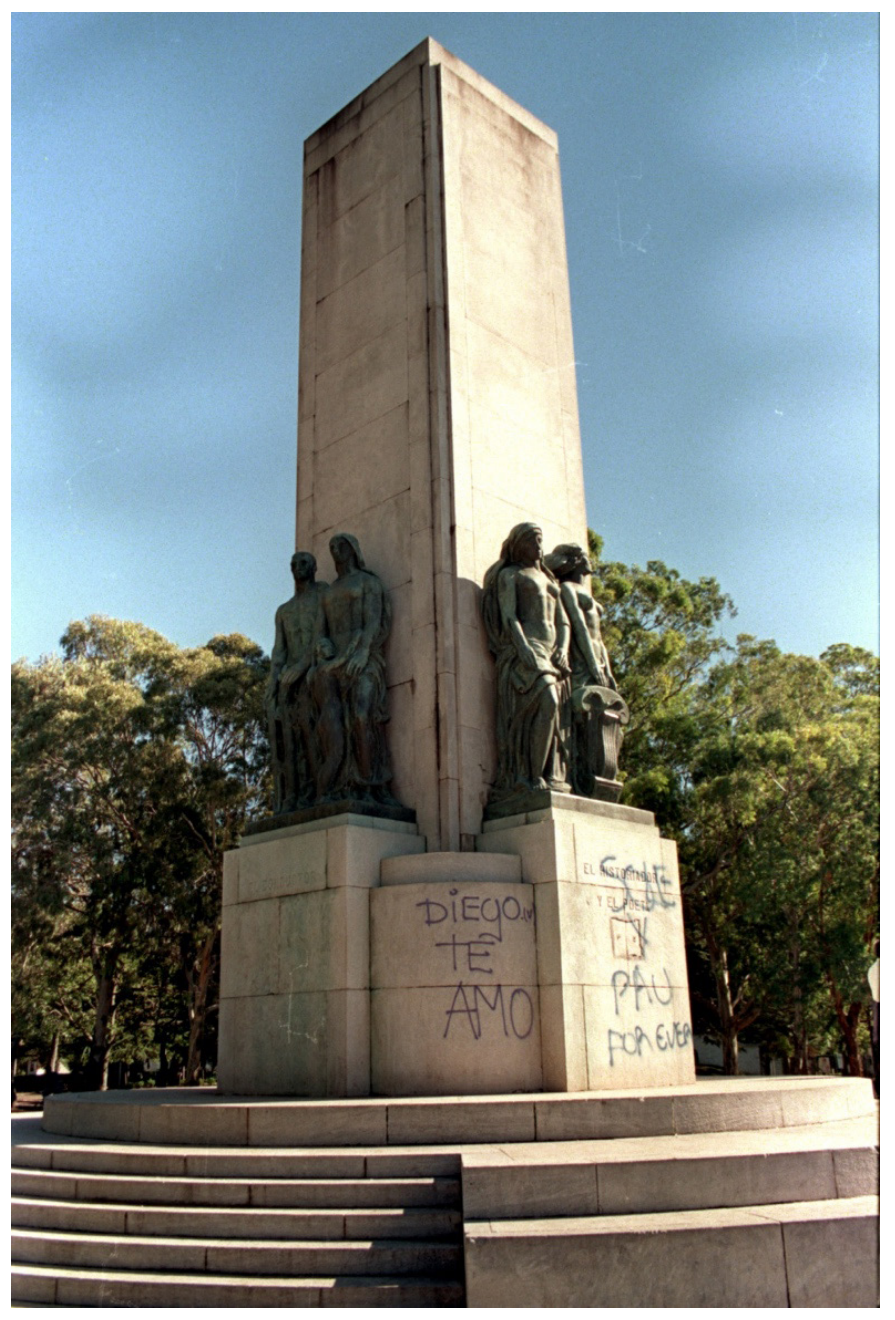

Imagen 1. Alfredo Bigatti, Monumento a Mitre, 1942. Fotografía del autor.

El diseño de Sforza dio al monumento a Dardo Rocha (imagen 2) un carácter decididamente arquitectónico. Quizás traspolando la idea de fundación a términos plásticos -como dijimos estaba haciendo simultáneamente Los Fundadores-decidió que la obra fuera básicamente fundamento, esto es, un gran basamento carente de estatua pero capaz de albergar imágenes y escenas figurativas en su mismo cuerpo. Rocha es ponderado a través de sus obras, expuesta en una envolvente 
figurativa continua que remata el volumen del monumento con figuras de gran escala (10 de $2,80 \mathrm{~m}$ y 3 de $3,40 \mathrm{~m}$ ) que constituyen el motivo central. Rocha aparece en un relieve pequeño, mientras el conjunto despliega superlativamente su obra (Imagen 2).

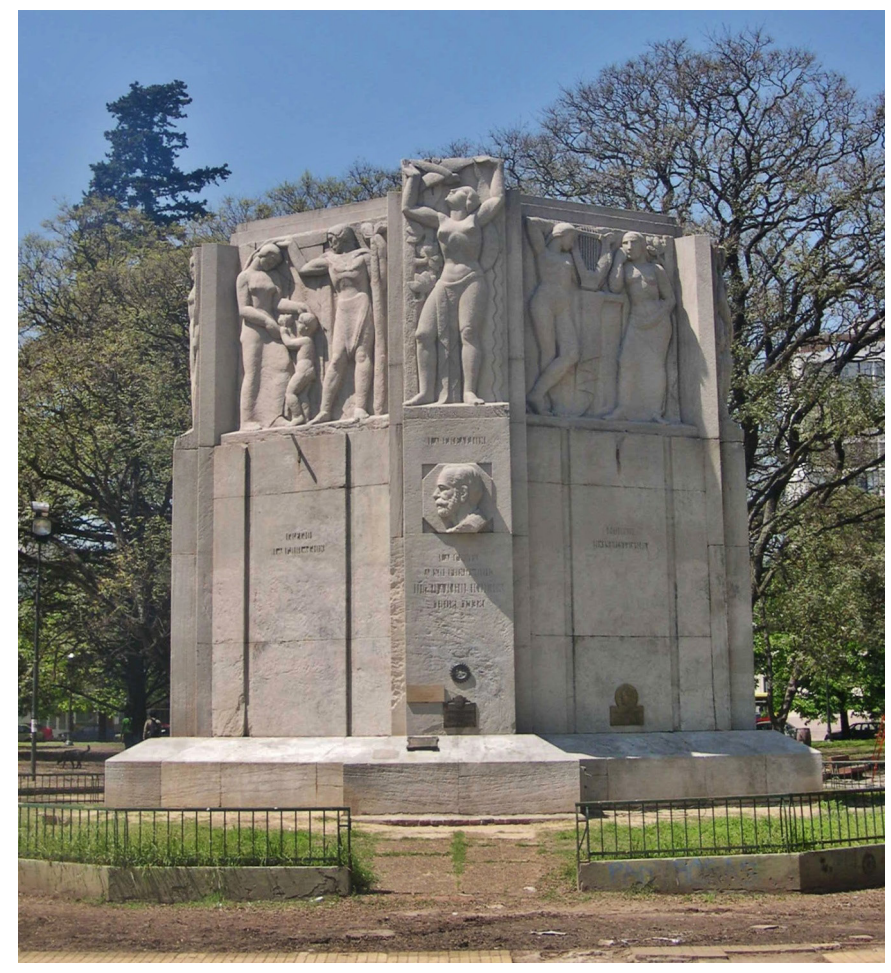

Imagen 2. César Sforza, Monumento a Dardo Rocha, 1934. Fotografía del autor.

Las figuras están tratadas en forma sintética, con volúmenes simples y robustos que ordenan las anatomía regular de las personificaciones, lo que condice con el carácter macizo y unitario del basamento que les sirve de soporte, metáfora del hecho conmemorado. El programa icnográfico concilia personificaciones de virtudes con grupos que representan hechos derivados de la fundación: en la cara principal (NO, a calle 7) sobre el relieve de Dardo Rocha de perfil se desarrolla la escena de la Creación (Imagen 3),

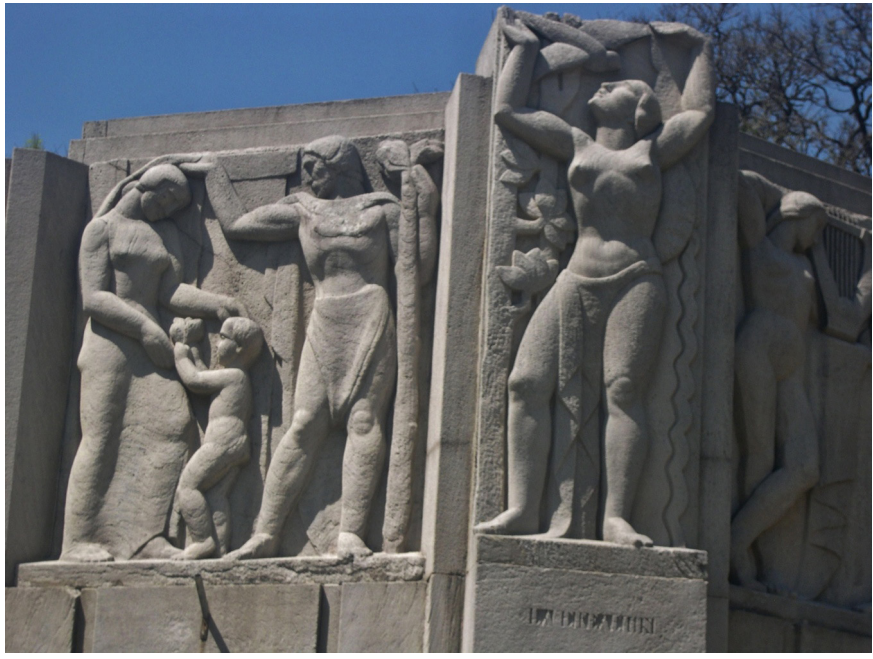

Imagen 3. César Sforza, Monumento a Dardo Rocha, La Creacion y Creció la población. Fotografía del autor.

personificada en una figura femenina tocada por un pájaro representando la inspiración y el espíritu. Hacia el norte el entrepaño siguiente se titula Creció la población, aludiendo al caudal inmigratorio atraído por la fundación, representada por una familia criolla cuyo hijo sostiene una rama florecida en alusión al atributo de san José y así trazando una analogía entre el grupo y la Sagrada Familia. En elángulo NE está personificada la Virtud cívica en una figura femenina frontal y desnuda portando una palma de la victoria. En el entrepaño este, las razones políticas de la fundación: Se conciliaron los poderes, donde las personificaciones de la Nación y la Provincia, son sus respectivos escudos se dan la mano bajo el árbol de la sabiduría. En el extremo SE se representa la consigna Consolidó la paz nacional 
(Imagen 4) en forma de una figura femenina con el torso desnudo que lleva como

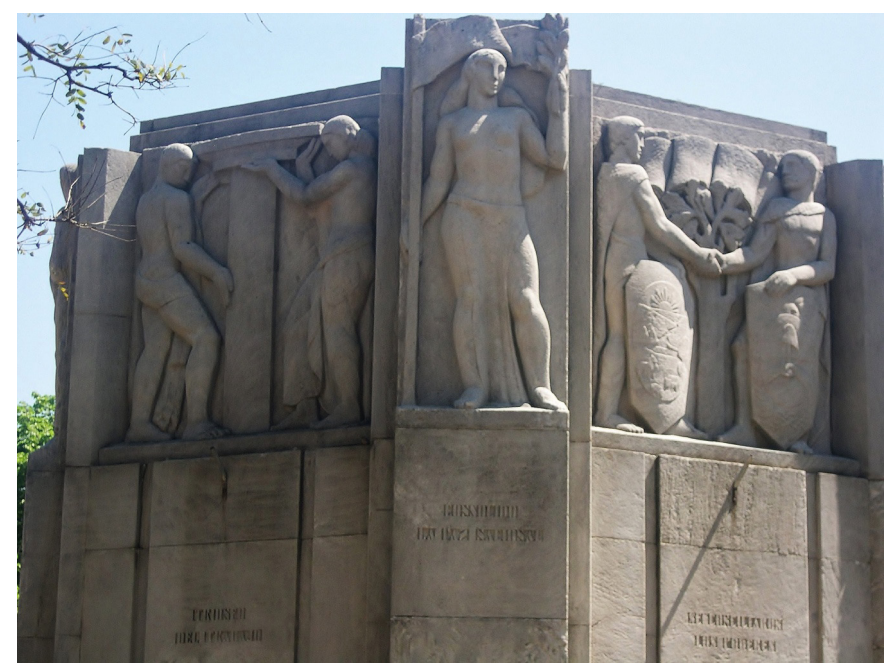

Imagen 4. César Sforza, Monumento a Dardo Rocha, El tiempo del Trabajo, consolidó la paz nacional y se conciliaron los poderes. Fotografía del autor.

atributos el olivo y la bandera. El panel Sur muestra El tiempo del trabajo, un hombre y una mujer toman parte en una construcción. El ángulo SO presenta la Voluntad triunfante como un personaje masculino de carácter hercúleo y que como el héroe griego porta una piel de león. Finalmente, el entrepaño oeste ilustra la Ciudad Universitaria personificada en las figuras femeninas de las Ciencia $y$ las Artes (Imagen 5) (González, 2001: 19-20).

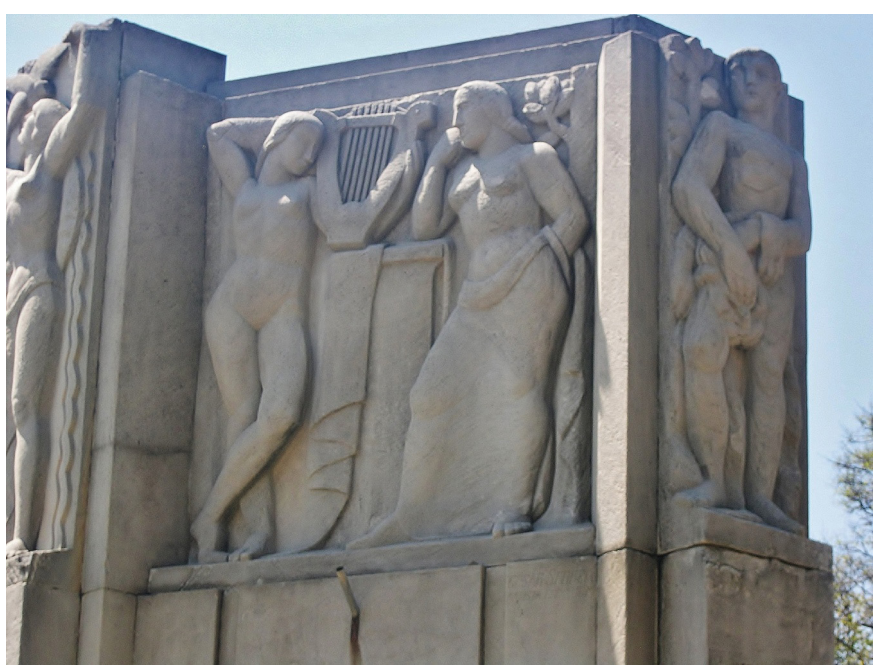

Imagen 5. César Sforza, Monumento a Dardo Rocha, Las Ciencias y las Artes, la Voluntad. Fotografía del autor.

El escultor recurre a la semántica de las personificaciones, pero éstas no ilustran primordialmente ideas generales, como es corriente en el género, sino acciones específicas derivadas del proceso de erección de la ciudad y que formaban parte de su imaginario. Desde una perspectiva formal, el bloque figurativo de Sforza recorre un camino similar al del programa iconográfico. Ya no se trata de la adopción de formas estandarizadas del repertorio genérico europeo, sino de una elaboración particular destinado a servir de soporte al conjunto narrativo. La solidez y la monumentalidad son, indudablemente, parte del sentido sugiriendo la firmeza del proyecto que para entonces había superado sus inconvenientes congénitos.

En el simple volumen las figuras se deslizan en un discurso claro y potente que interactúa y da vida a la severa masa de piedra. El conjunto exhala una sensación de seguridad y de autoconfianza en las 
que la propia historia es la gran protagonista, pero ahora vista con ojos propios. Los mismos materiales acompañan estos cambios: el mármol de Carrara y el Ravaccione característicos de la etapa anterior han sido reemplazados por la piedra Mar del Plata, que refuerza con su familiar color arenado el carácter local de la obra.

Desde mediados del sigloXIX los escultores de obras en espacio público, empleaban la combinación de un núcleo que exhibía al personaje con distintas alternativas que complejizaban el programa iconográfico en torno o sobre los basamentos, incorporando temas complementarios. Pero las formas de resolución utilizadas por Sforza plantean un espacio creativo muy diverso al de estos modelos académicos. En cierta forma puede verse en esta actitud una concepción histórica corrida hacia las características nacionales del proceso $y$, por el contrario, crecientemente alejada de la inscripción en un molde programático universal, que tanto el clasicismo como la Revolución Industrial y el modelo burgués y liberal europeo propugnaban. Las personificaciones antiguas, como signos de una belleza invariante, habían servido de portavoces de un programa civilizatorio de valor genérico, en parte heredero de la racionalidad laica que la Antigüedad representaba y que ahora cedía a una visión más interesada por las características locales de la historia y la problemática social y económica, es decir hacia una perspectiva que tenía su eje en el desarrollo endógeno. Esta mirada situada parece estar presente en la misma génesis del monumento.

\section{El régimen municipal}

El $1^{\circ}$ de enero de 1927 había asumido como intendente de La Plata Antonio Schifino (https:// www.concejodeliberante.laplata.gob.ar/Textos/ historial.html (Consultado el 20.10.2020) y este solo hecho consolidaba el orden político local. El municipio, que como dijimos estuvo por períodos a cargo de comisionados, parece adoptar un papel más relevante en el camino de la autodeterminación, como expresión de la consolidación de la ciudad sobre sus propios recursos y no ya como una simple herramienta del juego político nacional. La cuestión misma del alcance y forma del régimen municipal estaba en discusión y en tránsito de la concepción meramente administrativista que había caracterizado al siglo XIX bajo el nombre de "autarquía municipal", a una concepción que asignaba un rango decisorio más amplio a las autoridades municipales bajo el título de "autonomía municipal".

Como resultado de la ley Sáenz Peña (1912), el voto universal cobró vigencia a lo largo de la década del 20 en las elecciones comunales, hecho defendido en consonancia con la adopción de una perspectiva de autonomía municipal por radicales y demócrata-progresistas que impulsaron la sanción de Cartas Orgánicas municipales en concordancia con el proyecto de régimen municipal de carácter nacional presentado en la Cámara de Diputados ya en 1912 por Lisandro de la Torre. Como señala Antonio María Hernández “en este tiempo se comienza a democratizar el régimen municipal, como consecuencia de los cambios operados en el régimen político nacional, aunque ambos procesos no fueran idénticos" (Hernández, 
1997: 81-82). Naturalmente, el debate sobre los alcances del poder municipal era un indicador claro de las expectativas comunales respecto a sus propias incumbencias y controles.

En los años en que Sforza tallaba en piedra Punta Mogotes sus personificaciones, Rafael Bielsa publicaba su libro Principios del régimen municipal (1930) en el que defendía la autarquía, esto es el carácter exclusivamente administrativo del orden comunal, reservando para las provincias la autonomía y para el Estado nacional, la soberanía (Hernández, 1997: 85). Contrariamente, y justamente en la ciudad de La Plata, la defensa del derecho municipal a controlar y ordenar aspectos de su propia vida (gobierno, finanzas, poder de policía, elecciones) fue sostenida por las tesis de Adolfo Korn Villafañe en su artículo El poder municipal argentino: Teoría general y antecedentes históricos, publicado en el número 20 de la revista Humanidades en 1929.

La exacta concordancia cronológica entre ambos hechos, el debate sobre los alcances municipales y la erección de un monumento al fundador de la ciudad, parecen poder leerse en clave unitaria sin un gran esfuerzo de fantasía. El nuevo poder dado a los ciudadanos por el tránsito al sufragio universal y la consiguiente expectativa de incrementar así la participación en las diversas instancias de gobierno, junto a las nuevas condiciones particulares de La Plata, que remontaba hacía ya dos décadas la "desolación de los soñadores", según la expresión de Alcock, que había teñido los primeros tiempos, constituían un fundamento firme para avanzar en dirección al fortalecimiento de las instituciones locales y naturalmente, a la promoción de su representación simbólica. Erigir un monumento al fundador era proclamar el éxito de la fundación.

Aderezada la plaza hasta entonces olvidada y construido el monumento, ciertamente imponente en su volumetría simbólica y seguramente más en el contexto edilicio del momento, quedó expuesta a la vista la grandiosa prospectiva que Rocha había imaginado para la ciudad, bien que sin considerar las herramientas necesarias para alcanzarla. Inaugurado en 1934, luego de seis años y no de seis meses como se planteó en 1928, al fin el fundador mostraba o compartía su programa, que era el del 80: la pacificación del país a través de la resolución del conflicto entre Buenos Aires y las provincias, la repoblación mediante la apertura a la inmigración europea, el desarrollo de la producción, de las ciencias y de las artes. Todo salpicado con valores precisos para la obra, como la virtud cívica y la voluntad y con notas particulares del fundador y la ciudad en la Creación y la Ciudad Universitaria, carácter que tardíamente (1905) tomó en la vida platense el lugar que la industria y el comercio no habían hasta entonces ocupado.

\section{Epílogo}

En los meses en que se decidía la realización del reconocimiento a Dardo Rocha (mediados de 1928) la Argentina, recuperada de la crisis del 90 y de los coletazos de la la Guerra Mundial, había alcanzado su máximo caudal histórico de reservas: $m \$ n$ 1491,5 millones (Ortiz, 1997: 532). En los 10 años anteriores (desde 1919) el PBI se había incrementado a una tasa anual de 5,8\%, la inversión había 
crecido al 18, $4 \%$ por año y las exportaciones al $6,3 \%$. El consumo privado había aumentaba al $5,9 \%$ y los gastos fiscales el $4.3 \%$. El mercado laboral se expandía vigorosamente, asimilando los cientos de miles de inmigrantes llegados en esos años, los salarios reales crecieron el $10 \%$ en la década situándose por encima de los europeos y también lo hacía el empleo. Finamente, el Estado invertía fuertemente para mejorar la calidad de la educación pública y la salud. Como lo señala Javier Ortiz, de quien tomamos estos datos, una sensación de euforia daba ritmo a la sociedad: "la Argentina no sólo creció rápidamente, sino que este proceso contó con bases muy sólidas" (Ortiz, 1997: 528-530).

Esta confianza en la propia fuerza expresa la robusta y bien plantada arquitectura de la obra de Sforza que emerge como una roca de "bases muy sólidas", según la imagen de Ortiz, materializando en sus relieves el proceso que efectivamente se estaba dando: la expansión de la población, el trabajo y la educación. Paradójicamente, cuando la obra se emplazó, seis años más tarde de que se decidiera su encargo, las circunstancias habían cambiado dramáticamente como resultado de la crisis económica que siguió a la Gran Depresión desatada en octubre de 1929 en el plano internacional y en el terreno nacional, a la pérdida de la democracia producida por el golpe del general José Félix Uriburu contra el gobierno de Hipólito Irigoyen. Las sólidas bases ya no eran tales, pero el monumento perduró como signo de un momento efímero de la vida argentina y de la voluntad de la ciudad de materializar su propia entidad en esa corriente que crecía.

\section{Referencias citadas}

\section{Fuentes:}

Legislatura de la Provincia De Buenos Aires: Diario de sesiones de la Cámara de Diputados de la Provincia de Buenos Aires, Buenos Aires, Ley 4249/18.10.1934. Municipalidad de la Plata, Actas del Concejo Deliberante.

\section{Referencias citadas:}

Agulhon, M. (1994): Historia Vagabunda, Etnología y política en la Francia contemporánea, México, Instituto Mora.

Balestra, J. (1986): El Noventa, Buenos Aires, Hyspamérica.

Barcia, P. (1982): La Plata vista por viajeros 1882-1912, La Plata, Del 80 y Librería Juvenilla.

González, R. (2001): Programa de inventario y catalogación de esculturas en espacios públicos en la ciudad de La Plata, La Plata, Municipalidad de La Plata.

González, R. (2004): “La utopía abandonada”, I Concurso de Investigación en Historia de las Artes Visuales. Trabajos premiados, La Plata, Instituto de Cultura de la Provincia de Buenos Aires.

Hernández, A. M. (1997): "El régimen municipal", Nueva Historia de la Nación Argentina, 8, Buenos Aires, Planeta.

Ortiz, J. (1997), “La Economía”, Nueva Historia de la Nación Argentina, 8, Buenos Aires, Planeta. 


\section{Notas}

[1] El periodista inglés Theodore Child, por ejemplo, escribe en 1890 que, a diferencia de lo que ocurre en los Estados Unidos, aquí se ha creado una urbe sin industrias a excepción, subraya irónicamente, "a esta industria política, monopolio de los criollos y plaga de la República, La Plata debe su creación" (en Barcia, 1982: 183-184). 